\title{
Mentoring: A Strategy to Support Novice Early Childhood Educators
}

\author{
Laura K. Doan
}

Laura Doan is a lecturer in the early childhood education program at Thompson Rivers University, where she has taught for the last twelve years. She is a doctoral candidate through the University of Calgary, where she is studying leadership in postsecondary contexts. Research interests include the mentoring needs of novice early childhood educators, training needs of early childhood education mentors, and leadership in the field of early childhood education. Email: 1doan@tru.ca

The mentoring needs of novice early childhood educators are identified within the British Columbian context, where graduates do not receive formal mentoring. Following a description of the problem, a literature review is provided on the following themes: how mentoring facilitates a culture of learning; characteristics of successful mentors; and the mentoring process. Examples are drawn from mentoring programs in New Zealand and Worcester, England. Leadership implications are discussed with an emphasis on future research on mentoring in early childhood education.

Diploma programs that prepare early childhood educators for their profession can provide an excellent introduction to theory and practice; however, graduates often explain that they need support during their first year of work (Rodd, 2006). Like first-year elementary and secondary school teachers, early childhood educators report that a mentoring model where they connect with an experienced educator would be most effective as they transition into the role of a professional early childhood educator (Brindley, Fleege, \& Graves, 2000; Whitebook \& Sakai, 1995). When asked what would help to increase their confidence, competence, and professionalism, novice teachers identified mentoring as their first priority (Ontario College of Teachers, 2006). Moreover, novice teachers recognized the benefits of mentoring as "collaboration, feedback, observation, and sharing with experienced colleagues" (p. 8); experiences like these can help educators to avoid feeling overwhelmed, isolated, and uncertain (Feiman-Nemser, Carver, Schwille, \& Yusko, 1999; Noble \& Macfarlane, 2005). Novice educators involved in a mentoring program through the University of Worcester benefited from "support in the workplace, layers of mentoring support, relationship building, and interactions and communication" (Murray, 2006, p. 73). In contrast, early childhood educators in British Columbia are not involved in a formal mentoring program, and are potentially left on their own during a critical time in their careers when mentoring might be beneficial. The purpose of this article is to determine how mentoring might assist or ameliorate the stresses associated with beginning educators. The mentoring process will be discussed, with examples from programs in New Zealand and Worcester, England. Finally, leadership implications for establishing formal mentoring programs will be shared.

\section{Context}

Early childhood education programs rely on relationships between the student, the early childhood education instructor, and the sponsor educator. The early childhood education instructor teaches in a postsecondary institution and the sponsor educator works in the community alongside the student, supporting the student in their practicum by modelling skills, observing the student, and providing feedback. The early childhood education instructor and sponsor educator spend many hours with the early childhood education student, discussing matters of pedagogy and issues of practice, such as how to guide children's behaviour (Rodd, 2006). With the assistance of the sponsor educator and the instructor, the student takes on increasing levels of responsibility. The student is given feedback on a consistent basis and is supported in making any necessary changes to their practice. When early childhood education students graduate and begin working, these relationships change, and at present in the province of British Columbia, there is no defined structure to support novice early childhood educators.

When attempting to understand the needs of novice early childhood educators, it can be helpful to draw on theories of educator development. Katz (1972) proposed a theoretical model for the stages of early childhood educators (see Figure 1). The first stage, survival, as its name suggests, is where the educator simply tries to get through the day or week, and this can last up to one year. Katz wrote, "During this period the teacher needs support, understanding, encouragement, reassurance, comfort and guidance. She needs instruction in specific skills and insight into the complex causes of behaviour - all of which must be provided on the classroom site" (p. 4). What is key here is the on-site support the novice early childhood educator requires, making it important that the mentor is physically nearby to assist the novice in daily situations, such as how to guide children's behaviour, form connections with family members, and plan programming based on children's needs and interests. 


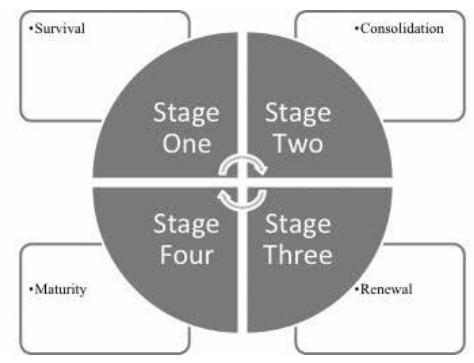

Figure 1. The four stages of the Katz model, modified from Katz (1972).

Katz (1972) went on to describe stage 2, consolidation, as a phase when educators are "ready to consolidate overall gains made during the first stage and to differentiate specific tasks and skills to be mastered next" (p. 5). This period is one where educators feel more confident and are able to focus less on themselves and more on the individual needs of the children. Katz described the third and fourth stages, renewal and maturity, as times when educators seek further professional development and ask deeper questions about topics such as philosophy and how change occurs.

In 2007 the Early Childhood Educators of British Columbia wrote a report entitled Developing a Strategy for Professional Leadership where they reported that "a mentoring framework is needed to help people take steps to be mentors" (Gay, 2007, p. 18). Additionally, it was suggested that Katz's (1972) developmental stages of early childhood educators be explored. Furthermore, the Organisation for Economic Cooperation and Development (2005) has suggested that teacher development be viewed as a continuum, with teachers receiving support at the beginning of their career in addition to ongoing professional development. It is possible that mentoring could be a useful strategy in helping novice early childhood educators to successfully enter the profession.

\section{Mentoring in Early Childhood Education}

In reviewing the literature on mentoring in early childhood education, the following themes have emerged: culture of learning, characteristics of successful mentors, and the mentoring process. These themes are elaborated below.

\section{Culture of learning}

Successful mentoring can result in a culture of learning, where knowledge gain occurs for both the mentor and the novice. Rodd (2006) points out that the early childhood profession has "endorsed informal and formal mentoring as a key leadership strategy because it focuses on helping practitioners to realize their professional potential" (p. 173). Rodd (2006) believes that most early childhood educators feel enthusiastic about their work and are eager to help others by sharing "their own knowledge, understanding, practice and expertise" (p. 173). Researchers have found that mentoring supports professional growth (Rodd, 2006), is a strategy for professional development (Bellm \& Whitebook, 1996), helps to promote attitudes of lifelong learning (Weaver, 2004), and assists in rising above "some of the shortcomings of current approaches to training early childhood practitioners" (Rodd, 2006, p. 172). Additionally, there are opportunities for shared learning among staff groups as opposed to learning that is occurring between mentoring dyads exclusively (Murray, 2006), making mentoring an opportunity for professional development that could impact the whole workplace, resulting in increased learning and collegiality among staff (Weasmer \& Woods, 2003).

\section{Characteristics of successful mentors}

Rodd (2006) identifies the following characteristics of successful mentors: "empathy and understanding, an interest in lifelong learning and professional development, sophisticated interpersonal skills, cultural sensitivity, understanding of the role of mentor, and considerable early childhood expertise" (p. 172). Hurst and Reding (2002) found the following to be important mentoring characteristics: "authenticity, gentleness, patience, consistency, positive attitude, teachability and enthusiasm" (p. 19). Specific skills connected with successful mentoring are "active listening, effective observations, reflective conversations, awareness of different learning styles, and adult/teacher development" (Rodd, 2006, p. 173). Callan (2006) describes the mentor as a "bridge between the academic forum and the day-to-day experience encountered by practitioners in early years settings" ( $p$. 8). Additionally, novice educators benefit from modelling by the mentor (Weasmer \& Woods, 2003). Ingersoll and Kralik (2004) found that some types of mentoring actions were more useful than others. These included working with a mentor from the same field, and having common planning time, opportunity to collaborate with other educators about instruction, and supportive communication from administrators.

\section{The mentoring process}

Mentoring occurs in a variety of forms, ranging from informal to formal and lasting a diverse amount of time. Mentors may be assigned to a particular novice or may be chosen by the novice themselves. In most cases, mentors are considered to have more experience than the novice, but it is possible for peers to mentor each other (Murray, 2006). In New Zealand, novice teachers are involved in a twoto five-year stage of induction before applying for fully registered teacher status (Aitken, Ferguson, McGrath, PiggotIrvine, \& Ritchie, 2008). These novice educators, referred to as provisionally registered teachers (PRTs), are assigned a mentor who is involved in "the provision of emotional support and encouragement; giving general guidance and suggestions; providing summative feedback; promoting reflective questioning and conversation; supporting goal setting; and generally advocating for the PRT and her progress" (Aitken et al., pp. 25-26). During this time, the PRT is involved in a prearranged program of "mentoring, professional development, observation, targeted feedback on their teaching, and regular assessments based on the standards for full registration" (p. 1). The PRTs portrayed their mentoring experience with the mentor teacher as "vital to their profession and to the eventual completion 
of their teacher registration" (p. 25).

The relationship between the mentor and the novice educator is important, and building trust is a crucial first step (Ebbeck \& Waniganayake, 2003). Some novice educators are reluctant to ask for help, despite the fact that they need it, making it all the more important for the novice to know that the mentor understands their needs and is there to support them (Liberman, Hanson, \& Gless, 2012). One program in Worcester, England, uses the term professional critical friend to describe the mentor, one who provides "front-line peer support" (Murray, 2006, p. 64). The Worcester program is based on the premise that mentoring supports adult learning in the workplace by facilitating experiential learning, which helps the novice educator to "draw personal meaning and value" through the context of their work site (p. 64). The professional critical friend is typically a workplace colleague and may be a peer with the same qualifications as the novice educator. Novice educators select their own mentor, giving them the opportunity to choose a mentor they trust and feel comfortable with. One novice educator spoke about the support she received from her mentor:

I have gone through the traumas. My mentors made me realise it was manageable. I might not have got to the end and was tempted to "throw in the towel' at times. My mentor helped those times. There was a sense of family and community with the mentor and the college. (Murray, p. 75)

Mentoring practices differ depending on the interaction style of the mentor and the needs of the novice educator. Novice educators benefit from mentors who are responsive to both their needs as a novice educator and the context in which the mentoring is occurring (Murray, 2006). A critical element of the mentoring process and educator development is reflection, and mentors play a pivotal role in facilitating it (McCormick \& Brennan, 2001). Mentors and novice educators should meet regularly; during these times, the mentor can invite the novice to reflect on their daily practice with children, families, and educators. This reflection may include recognizing areas of strength and growth, and identifying goals. What is important is that, as the novice educator enters the profession, they are not alone (Murray, 2006).

\section{Leadership Implications}

When early childhood educators are involved in mentoring, leadership ability is built within the profession; this is something that needs to happen for early childhood education to achieve the same professional status as other occupations (Rodd, 2006). Additionally, mentoring is one way to help novice early childhood educators "to perceive themselves as leaders in the profession" (p. 34), which some may be reluctant to do. Furthermore, there are opportunities for early childhood faculty in postsecondary institutions to explore and develop leadership capability through mentoring programs. Researchers who can partner with educators to develop and research a mentoring program can provide leadership by helping to bridge the gap between researchers and practitioners, which is of particular interest in early childhood education, where many educators do not embrace a research culture (Rodd, 2006). Puig and Recchia (2008) found that novice educators were feeling overwhelmed and desired further connections with their university faculty. They wrote, "Bringing new teachers and professors together through these forums of support creates meaningful connections between research and practice as well as teacher training and teacher work" (p. 342). Maintaining relationships between faculty and graduates can be a benefit to all stakeholders in the early childhood education community.

\section{Conclusion}

As novice early childhood educators enter the profession, they experience "survival," as Katz (1977) described, a time when educators could benefit from hands-on support through a mentor in the workplace. Novice early childhood educators can gain support from mentors who demonstrate gentleness, patience, and a positive attitude, and are able to encourage reflective thinking (Hurst \& Reding, 2002; Rodd, 2006). Furthermore, there are advantages for staff who become involved in mentoring, as a culture of learning can develop where early childhood educators learn together (Rodd, 2006). Mentoring is a relevant topic for early childhood educators, and pursuing research on the mentoring needs of novice early childhood educators could lead to increased levels of workplace satisfaction for mentors and novice early childhood educators, including less burnout, greater understanding of leadership in early childhood education, and better quality care (Bella \& Bloom, 2003; Rodd, 2006).

\section{References}

Aitken, H., Ferguson, P. B., McGrath, F., Piggot-Irvine, E., \& Ritchie, J. (2008). Learning to teach: Success case studies of teacher induction in Aotearoa New Zealand. Wellington, NZ: New Zealand Teachers Council.

Bella, J., \& Bloom, P. J. (2003). Zoom: The impact of early childhood leadership training on role perceptions, job performance, and career decisions. Wheeling, IL: Center for Early Childhood Leadership.

Bellm, D., \& Whitebook, M. (1996). Mentoring for early childhood teachers and providers: Building upon and extending tradition. Young Children 52(1), 59-64.

Brindley, R., Fleege, P., \& Graves, S. (2000). A friend in need: Mentorship and community. Childhood Education, 76(5), 312-316.

Callan, S. (2006). What is mentoring? In A. Robins (Ed.), Mentoring in the early years (pp.5-16). London, UK: Paul Chapman.

Ebbeck, M., \& Waniganayake, M. (2003). Early childhood professionals: Leading today and tomorrow. Marrickville, NSW: MacLennan \& Petty.

Feiman-Nemser, S., Carver, C., Schwille, S., \& Yusko, B. (1999). Beyond support: Taking new teachers seriously as learners. In M. Scherer (Ed.), A better beginning: Supporting and mentoring new teachers (pp. 3-12). Alexandria, VA: Association for Supervision and Curriculum Development

Gay, C. 2007. Developing a strategy for professional leadership. Early Childhood Educators of British Columbia Strategy Session. Retrieved from http:// www.ecebc.ca/leadership/files/ECEBC_Strategy_ Session.pdf

Hurst, B., \& Reding, G. (2002). Teachers mentoring teachers: Fastback 493. Bloomington, IN: Phi Delta Kappa International.

Ingersoll, R., \& Kralik, J. (2004). The impact of mentoring on teacher retention: What the research says. Denver, CO: Education Commission of the States.

Katz, L. (1972). Developmental stages of preschool teachers. Urbana, IL: Educational Resources 
Information Centre Clearinghouse on Early Childhood Education.

Liberman, A., Hanson, S., \& Gless, J. (2012). Mentoring teachers: Navigating the real-world tensions. San Francisco, CA: Jossey-Bass.

Puig, V. I., \& Recchia, S. (2008). The early childhood professional mentoring group: A forum for professional learning. Journal of Early Childhood Teacher Education, 2, 340-354.

McCormick, K. M., \& Brennan, S. (2001). Mentoring the new professional in interdisciplinary early childhood education: The Kentucky teacher internship program. Topics in Early Childhood Special Education, 21, 131-149.

Murray, J. (2006). Designing and implementing a mentoring scheme: University of Worcester SureStartrecognized sector-endorsed foundation degree in early years. In A. Robins (Ed), Mentoring in the early years (pp.63-78). London: Paul Chapman.

Noble, K., \& Macfarlane, K. (2005). Romance or reality?: Examining burnout in early childhood teachers. Australian Journal of Early Childhood, 30(3), 53-58.

Ontario College of Teachers. (2006). New teacher induction: Growing the profession. Toronto, $\mathrm{ON}$ : Author.

Organisation for Economic Cooperation and Development. (2005). Teachers matter: Attracting, developing, and retaining effective teachers. Paris, France: Author.

Rodd, J. (2006). Leadership in early childhood (3rd ed.) New York, NY: Open University Press.

Weasmer, J., \& Woods, A. M. (2003). Mentoring: Professional development through reflection. The Teacher Educator, (39)1, 64-77.

Weaver, P. E. (2004). The culture of teaching and mentoring compliance. Childhood Education 80(5), 258-260.

Whitebook, M., \& Sakai, L. (1995). The potential of mentoring: An assessment of the California early childhood mentor teacher program. Washington, DC National Center for the Early Childhood Work Force.

\section{WWFANTIODDLER

\section{Become a}

Montessori Teacher

... without missing work

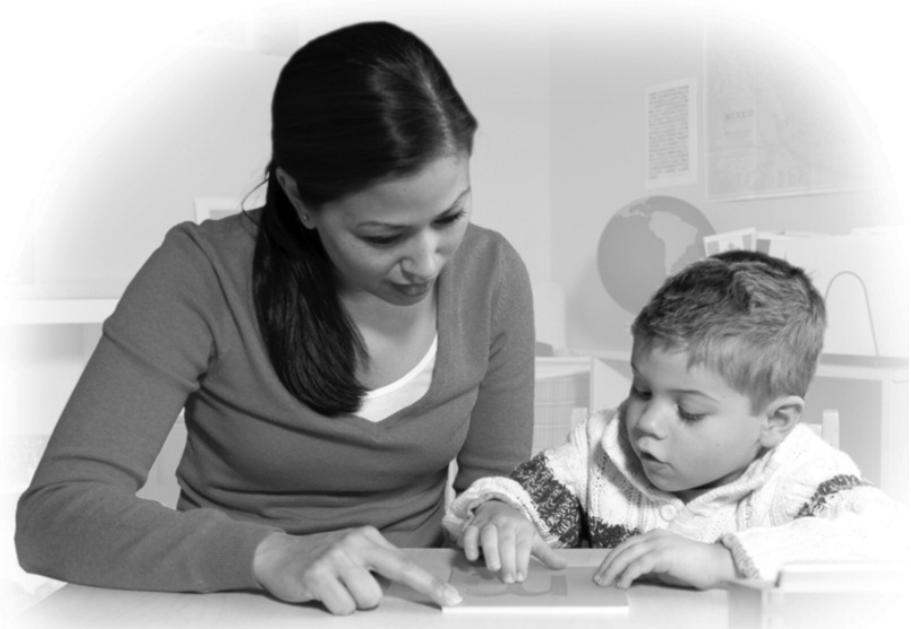

ACCESSIBLE

AFFORDABLE

The convenience of distance education

FLEXIBLE

Start any time on your own schedule

\section{VALUABLE}

Enrich or transform your center with Montessori

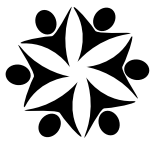

Toll-free: 1.877.531.6665 info@montessoritraining.net www.montessoritraining.net

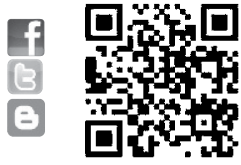

